\title{
REPRESENTAÇÕES SOBRE O ESCOTISMO, O EXÉRCITO E A EDUCAÇÃO CORPORAL NO BRASIL: UM ESTUDO A PARTIR DE TESES APRESENTADAS EM CONGRESSOS ESCOTEIROS
} (1922-1923)

\author{
REPRESENTATIONS ABOUT SCOUTING, THE ARMY AND BODY EDUCATION \\ IN BRAZIL: A STUDY BASED ON THESES PRESENTED IN SCOUTING \\ CONGRESSES (1922-1923)
}

\begin{abstract}
REPRESENTACIONES SOBRE EL MOVIMIENTO SCOUT, EL EJÉRCITO Y LA EDUCACIÓN CORPORAL EN BRASIL: UN ESTUDIO A PARTIR DE TESIS PRESENTADAS EN CONGRESOS DE SCOUTS (1922-1923)
\end{abstract}

\author{
Carlos Herold Junior*, Alexandre Fernandez Vaz ${ }^{* *}$
}

\section{Palavras-chave} Movimento escoteiro.

Corpo.

História

do século XX.

Educação.

Keywords

Scout Movement.

Body.

History of the

20th Century.

Education.

Palabras clave Movimiento Scout.

Cuerpo.

Historia del siglo XX.

Educación.
Resumo: Estudamos a educação corporal na expansão do escotismo brasileiro no início do século XX. A partir de teses publicadas em congressos escoteiros que aconteceram nos anos 1920, analisamos as representações sobre corpo e educação com as quais os congressistas estimularam e justificaram o valor das práticas escoteiras. Como resultado, verificamos uma grande ênfase em atividades corporais que deveriam ser praticadas no escotismo seguindo os passos da "pedagogia científica". Por isso, era defendido um afastamento da forma como o mundo militar utilizava o corpo para a formação de seus contingentes.

Abstract: We study body education within the expansion of Brazilian Scouting at the beginning of the 20th century. Based on theses published in Scouting Conferences in the 1920s, we analyze representations about body and education with which participants encouraged and justified the value of scouting practices. We found a large emphasis on body activities that should be practiced in Scouting according to "scientific pedagogy". Therefore, those views advocated a departure from the way the military world used the body to form their troops.

Resumen: Estudiamos la educación corporal en la expansión del Movimiento Scout brasileño a principios del siglo XX. A partir de tesis publicadas en congresos de Scouts que fueron realizados en los años 20 , analizamos las representaciones sobre cuerpo y educación con la que los congresistas alentaron y justificaron las prácticas del Movimiento Scout. Como resultado, observamos un gran énfasis sobre actividades corporales que deberían ser practicadas en el Movimiento Scout siguiendo los pasos de la "pedagogía científica". Por eso, se abogó por un alejamiento de la forma en que el mundo militar utilizaba el cuerpo para la formación de sus contingentes.
*Universidade Estadual de Maringá (UEM/CNPq). Maringá, PR, Brasil. E-mail: carlosherold@hotmail.com

** Universidade Federal de Santa Catarina (UFSC/CNPq). Florianópolis, SC, Brasil. E-mail: alexfvaz@uol.com.br

Recebido em: 18-08-2015 Aprovado em: 20-09-2015 (c) (i) () Licence 


\section{CONSIDERAÇÕES INICIAIS}

Taborda de Oliveira e Linhales (2011, p.389) observam que a educação do corpo é "uma das marcas mais tangíveis da difusão mundial da educação primária entre as décadas finais do século XIX e as primeiras décadas do século XX". Para pesquisar essa "dimensão ainda pouco explorada nos estudos históricos", é necessário assumir que naquele momento a educação corporal foi alvo de "discursos, dispositivos, práticas e saberes distintos em sua origem” (TABORDA DE OLVEIRA; LINHALES, 2011, p.389). Dentre essas práticas e discursos, está o escotismo.

Criado na Inglaterra por Robert Baden-Powell em 1907, o escotismo não foi um movimento educacional diretamente escolar. Entretanto, seus criadores estavam muito atentos ao que acontecia na escola, sobretudo, no tocante às práticas corporais e ao potencial formativo que se supunha haver nelas. Lideranças, chefes de grupos escoteiros e uma variada gama de simpatizantes, frequentemente, referiam-se aos problemas da instituição escolar para contrapor a relevância de suas proposições, tida como evidente na grande atenção que prestavam ao corpo em sua plataforma pedagógica.

Nessa referência à educação corporal, a formação e a divulgação do escotismo estiveram muito relacionadas à instituição militar. Alves (2010) nos esclarece que a vinculação dos militares à educação exerceu papel fundamental na "História de construção da cultura escolar moderna" (ALVES, 2010, p.129), ladeando a importância da Igreja na formatação dessa forma educacional. $\mathrm{O}$ apelo dessa importância no início do século XX no Brasil fez com que Horta $(1994$, p.7) assumisse "As Forças Armadas como 'educadoras do povo"'. Essas considerações sustentam uma afirmação, feita por nós, em um estudo anterior:

Tendo como inspiração o campo de batalha, a preocupação em fortalecer 0 corpo para consolidar valores morais e propagar visões de mundo não foi uma descoberta do final do século XIX. [...] o guerreiro valoroso ou o soldado valente tem importância como um ideal formativo a ser atingido pela educação em diferentes épocas (HEROLD JUNIOR; VAZ, 2015, p.1019).

No interior do escotismo, ponderar a proximidade e o distanciamento em relação ao "ideal formativo" do exército ocupou os fundadores do movimento e, academicamente, tornouse uma inquietação fonte de grandes debates, sobretudo, depois da publicação do texto de Springhall (1971), que investigou a relação entre escotismo e militarismo na Inglaterra. No contexto brasileiro, as pesquisas que temos feito oferecem-nos condições de defender que "As formas como o escotismo foi absorvido e praticado no Brasil também apresentaram a tentativa de pensar as atividades corporais escoteiras na tênue demarcação entre o pedagógico e 0 militar" (HEROLD JUNIOR; VAZ, 2015, p.1020).

Este artigo objetiva aprofundar as reflexões acima, escrutinando as tentativas dessa demarcação no contexto pedagógico da educação corporal escoteira da década de 1920 no Brasil. 0 esforço de valorizar a dimensão pedagógica do escotismo por meio das atividades corporais sustentou-se em uma crítica às práticas que aproximaram os grupos escoteiros do exército, embora características militares das práticas e dos objetivos da formação escoteira não fossem descartadas. Mostraremos que no interior do escotismo suas origens militares imbricam-se ao forte apelo modernizante de seus termos pedagógicos, encetando uma tensão entre a formação do cidadão e a formação do soldado. Evidenciaremos que a aproximação 
do escotismo à pedagogia ocorreu na defesa da utilização de práticas corporais como ginástica, jogos e esportes, distanciados de conotações caracteristicamente militares em seus procedimentos, em que pese à manutenção do apelo formativo da tradição educacional existente no exército consoante à formação cívica e moral. Essa tradição, cara aos chefes escoteiros e a toda sociedade brasileira de então, manteve-se presente em sua importância na concretização da modernidade pedagógica, aqui caracterizada na ênfase dada ao corpo.

Pensando o contexto francês, Bourzac (2004) endossa a valia que o entendimento da tensão acima pode ter para a realidade brasileira. Ao notar um declínio na importância do exército na Educação Física francesa no final do século XIX e início do XX ele afirma: "II s'agit de dissocier les exercises physiques et leur finalité militaire. C'est um facteur décisif..." (BOURZAC, 2004, p.283). Essa mesma "dissociação" foi um ponto importante da reflexão pedagógica no contexto brasileiro na segunda década do século $X X$, o que nos leva a avaliá-la a partir dos debates produzidos no interior do escotismo. Para tanto, não perdemos de vista as advertências que Ferreira Neto e Schneider (2010, p.164) elaboram ao estudar a Educação Física especificamente escolar do período: para os autores, foi justamente o "impedimento" do "modelo da caserna" nas práticas corporais escolares que fizeram ampliar o "controle militar do ensino", mesmo que adaptado ao "tempo e espaço escolar". Do mesmo modo, no escotismo as reservas apontadas em relação ao exército não anularam a presença de uma "cultura militar" (ALVES, 2010) no impulso aos apelos modernizantes da pedagogia escoteira, tal qual como ela era "dada a ler" (CHARTIER, 2002) por parte de seus dirigentes. Isso pode nos ajudar a pensar a grande aceitação do escotismo por parte de pedagogos e de militares.

Como base empírica para este trabalho, utilizamos teses apresentadas no Primeiro e no Segundo Congresso Escoteiro do Brasil, realizados em 1922 e 1923, no Rio de Janeiro. Elas foram publicadas em um mesmo volume em 1923, sendo que as teses do segundo congresso são apresentadas na publicação antes das do primeiro. Para a organização do texto desconsideraremos em qual dos dois eventos as teses foram apresentadas, aproximando-as ou distanciando-as pela forma com que colocam a educação corporal em destaque.

Essas fontes são estudadas sob o crivo do que Chartier (2002) chama de representação. Essa opção teórica se justifica pela possibilidade de se buscar, em diferentes posicionamentos, pontos de continuidade e de ruptura no interior de um determinado grupo de atores educacionais em seus esforços para pensarem as práticas formativas escoteiras. Veremos que, ao "representarem" o que acreditavam ser o "verdadeiro" escotismo, gerou-se uma tensão entre "ser" e "dever ser" dessas práticas na realização de variadas ambições formativas circulantes na sociedade como um todo, bem como a relevância das atividades corporais para concretizar tais intenções. Estimulados por Carvalho e Hansen (1996, p.15), pensamos as porosidades entre educação corporal, escotismo e exército evitando a "generalidade trans-histórica de categorias mágicas como "influência", "imitação" e "transplante de ideias". Essas porosidades serão tomadas como "práticas datadas", manifestas como "representações de práticas que resultam de práticas de representação" (CARVALHO; HANSEN, 1996, p.15).

As análises estruturam-se em duas partes: na primeira, abordamos as representações relativas ao valor educacional do escotismo, sua importância para a melhoria das instituições educacionais existentes e o fato de o movimento valorizar, intensamente, a educação por meio de atividades corporais, desde que distanciadas do mundo militar. Na segunda parte, verificamos que uma das principais inquietações dos congressistas dava-se em relação às 
aproximações e aos distanciamentos entre escotismo e exército, bem como às dificuldades que o jogo entre hesitações e certezas a respeito impunha à caracterização do escotismo como "pedagogia moderna" ao abordar o corpo e sua educação.

\section{REPRESENTAÇÕES SOBRE O ESCOTISMO, A EDUCAÇÃO DO CORPO E A PEDAGOGIA MODERNA.}

A primeira categorização de representações que podemos definir na leitura das teses justifica a importância formativa do escotismo estar calcada na possibilidade de o movimento lutar contra uma situação de crise moral. Essa crise moral era avaliada como resultante do amolecimento corporal gerado pela "vida moderna".

A formação do caráter significava educar moral e fisicamente "uma juventude fraca e débil de vontade" (FORTUNA, 1923, p.185-186). Esclarecia-se a dificuldade de realizar essa necessária formação sem "tirar a creança da atmosphera carregada das cidades" para colocála junto ao "convívio vivificante da natureza" (FORTUNA, 1923, p.185-186). Fazer frente a tal debilidade junto à natureza também significaria "trazer a educação á pratica, fazendo-a deixar os ethereos pincaros da theoria" (FORTUNA, 1923, p.185-186). No desenho de um panorama em que aparecia uma grande e "amarga desillusão do futuro da Patria", Gabriel Skinner (1923) via a juventude brasileira formada como "patriciosinhos", marcados por uma "triste figura moral e physica". Destacavam-se os traços "esqualidos, viseira cahida", agravados pelo fato de muitos serem "já fumantes inveterados", e que consumiam seu tempo como "terriveis jogadores de futeból nas ruas" (SKINNER, 1923, p.219). Compunha essa decadência o fato de a força e a resistência do corpo serem suplantadas pela exigência de qualidades intelectuais, em uma época em que o intelecto era mais solicitado que o vigor e que a capacidade de agir: "[...] 0 apuro cerebral, o requinte intelectual, são o mal da época, porque esquecem as necessidades do corpo" (RAMOS, 1923, p.242).

Essa situação, longe de ser mera especulação sobre os destinos da humanidade, de forma geral, e do Brasil, em particular, eram denúncias dirigidas, principalmente, aos jovens. Criticava-se que "[...] se cometem os maiores desatinos, as maiores extravagâncias, em que se não medem as conseqüências destes passos mal dirigidos" (RAMOS, 1923, p. 242-243). Era necessário o contorno da ociosidade, um "terreno pantanoso onde proliféram e vivem miríades de miasmas":

\footnotetext{
Não podeis dispensar a cultura física; não podeis desprezar os exercícios físicos; não podeis afasta-los das praticas qüotidiânas! Nos nossos dias, e mesmo em todos os tempos, a cultura do espirito tem sido o ideal elevado, e deve mesmo estar acima da cultura fisica. Mas, mesmo assim, não é bem, nem util que esta seja abandonada e esquecida [sic] (RAMOS, 1923, p.245).
}

A necessidade da "cultura física" não significava o abandono da "superactividade intelectual". Argumentava-se que os aspectos morais e os físicos, a dimensão material e a espiritual, não se antagonizavam. 0 antagonismo era um fruto equivocado de uma "época de crise". A consideração do "equilíbrio" era impossibilitada, pois, "hodiernamente, tais e tantas são as obrigações, que, dificilmente, o corpo merece os cuidados que lhe são devidos" (RAMOS, 1923, p.243).

A força e a capacidade desagregadoras da crise moral constatadas nas teses eram balanceadas pela crença em sua superação por meio do escotismo. A aceitação do escotismo e 
sua ênfase nas atividades corporais eram expressão da maneira como o "mundo inteiro", até os "mais recônditos recantos da Terra" (SODRÉ; SKINNER, 1923, p.146), assumiam a necessidade de moralizar a juventude por meio do corpo e de suas atividades. $O$ alcance conseguido pelo escotismo e o fato de ele sublinhar a educação corporal como base das qualidades volitivas e intelectuais para a reversão da situação de crise teve outra consequência: 0 impacto nas estruturas escolares, evidenciando os limites dessas instituições e a necessidade de que nelas o desenvolvimento de qualidades viris tivesse lugar. 0 escotismo não era apenas uma nova "modalidade pedagógica", ou não poderia ser encarado, simplesmente, a partir do "ponto de vista restrito da técnica educativa" (CURSON, 1923, p.58). O escotismo seria um "sistema de educação" diferente de qualquer outro. Essa diferença tornava as atividades do movimento escoteiro uma possibilidade de luta contra todo um conjunto de traços reprováveis nas práticas escolares de então. 0 mundo da escola era caracterizado como um "monótono suceder das classes de uma escola do tipo ao qual, ainda hoje, a maioria pertence", em que pese à existência de uma "pedagogia scientifica, dos fundadores das chamadas 'escolas novas' e dos radicais da pedagogia" (CURSON, 1923, p.58). No interior dos grupos escoteiros, a individualidade dos meninos era um elemento ativo, "responsável pela própria educação" (p.58), o que estimulava as mais variadas iniciativas. Em tom de crítica, constatava-se que nas escolas a situação era bem diferente: "Na escola, o critério oposto. Não se a cria a personalidade. O professor é quem vai, quase que abstraindo do aluno, pela craveira do programa [...]" (CURSON, 1923, p.58).

A escola também era criticada por não permitir às crianças que brincassem ao ar livre, com liberdade para suas "correrias" e "algazarras". Nem mesmo no recreio elas teriam a possibilidade de se portarem como um "bom animal que, instintivamente, desejaria ser" (CURSON, 1923, p.59). Já o escotismo, todavia, "deixa a criança expandir-se à vontade ao ar livre, tanto quanto ela precisa e como precisa; satisfaz-lhe as suas tendências românticas, fazendo-a viver uma vida paralela de aventuras" (CURSON, 1923, p.59).

Benjamin Sodré, ao relatar a tese de Curson e dar seu parecer sobre ela, endossa as análises que leu. Afinal, na escola "nada mais se faz do que procurar obter que os meninos aprendam alguma cousa com que possam ser approvados nos exames de fim de anno" (SODRÉ, 1923, p.66). O endosso também comungava com o valor do escotismo para reverter essa situação:

"O escotismo é uma escola completa de educação", estamos nós sempre a repetir. $E$, realmente, sem ser propriamente uma escola, não prendendo a creança senão nas suas horas de lazer, procura completar as falhas de sua educação, sob 0 tríplice ponto de vista - intellectual, physico e moral (SODRÉ, 1923, p.99).

A assunção da possibilidade de o escotismo remediar esses problemas e fazer as práticas educacionais acompanharem o que já preconizava a "pedagogia científica" dava ao movimento criado por Baden-Powell a condição de ser um "método" "inteiramente novo e de um valor nunca attingido" (SODRÉ; SKINNER, 1923, p.146).

\section{ESCOTISMO E A EDUCAÇÃO CORPORAL REPRESENTADA COMO "CIENTÍFICA".}

Dentro da escola, a força da "novidade escoteira" era o valor dado à educação por meio das atividades corporais. Skinner (1923, p.129) ponderava que se a invenção de BadenPowell fez sentido no contexto inglês pelo fato de lutar contra a falta de energia e moral dos 
jovens, no Brasil o escotismo teria uma missão ainda mais difícil e nobre pela maior dimensão do problema que aqui se observava.

Havia avaliações menos pessimistas da situação da educação corporal da escola brasileira no início do século XX. Sem esquecer que "Entre nós ainda não estão bem comprehendidos a razão e os effeitos da gymnastica", era afirmado que "[...] no Brasil, graças á intelligencia e bôa vontade de alguns homens, há varias escolas de gymnastica" (MONZON, 1923, p.70). Por sua vez, também se via que essa educação ganhava importantes espaços na sociedade. Afinal, "A ideia da educação physica parece-nos já é uma idéa vencedora, não só nos estabelecimentos de ensino e nas sociedades sportivas, como tambem entre nós, escoteiros" (TORRES, 1923, p.77). Torres defendia a necessidade de o jovem ter um organismo em condições de lutar pela sua própria vida, em um tempo marcado pela "inconstância e volubilidade da fortuna". Não se tratava, simplesmente, de cultivar a força corporal, mas uma "Cerebração esclarecida em organismo sadio, resistente e inflexível", assumidas como "predicados indispensaveis ao escoteiro, para não falsear a sua missão cada vez mais elevada e complexa" (TORRES, 1923, p.77). É um pensamento que também encontramos em Skinner:

O Escotismo dá à educação physica da juventude um caracter essencialmente pratico e utilitario, collimando, assim, o seu objectivo: um corpo sadio e forte alliado a uma intelligencia e inteireza de caracter invejavel (SKINNER, 1923, p.218).

A educação corporal proposta como uma das principais preocupações do escotismo levaria as crianças e os adolescentes a possuírem "virtudes viris" que os tornassem "integralmente fortes". Ao mesmo tempo, essas "virtudes viris" fariam esses "homens perfeitos" levar "no espírito noções claras e positivas de uma nova e auroral concepção de vida e belleza em ação..." (SKINNER,1923, p.218).

Já para Barros, a importância da educação corporal escoteira dava-se pela valorização dos "sports". A prática esportiva era uma "[...] vanguarda de todas as boas iniciativas tendentes a melhorar a mocidade, a raça, a pátria", com a vantagem de ser "uma formula mágica, que os (os jovens) faz vibrar, lembrar as grandes façanhas dos campeões..." (1923, p.226). Esse último ponto seria vital, pois coadunava-se com a postura educacional do escotismo, tendente a seguir a "pedagogia científica" que via na motivação de quem aprende o principal motor que levaria ao sucesso das práticas educacionais. Isso também deveria ocorrer com as atividades do corpo, a serem praticadas "agradavelmente, com interesse, com enthusiasmo" (BARROS, 1923, p.231-232).

Entretanto, notamos a existência do cuidado de se advertir que "nem mesmo por sombras, que os escoteiros devem passar os seus dias livres em praça de sports; não!" (BARROS, 1923, p.232). Exprimia-se, desse modo, uma contrariedade às contendas que aconteciam nas ruas. A consideração pedagógica mais importante era fazer com que os "sports" fossem praticados, preferencialmente e apenas, na sede de cada grupo (BARROS, 1923, p.232).

Ao lado da defesa feita sobre o valor da educação corporal no escotismo, bem como da "maneira correta" de realizá-la por meio dos "sports", algumas teses buscam evidenciar a necessidade dessa educação acontecer baseada na ciência. A possibilidade de um método "verdadeiramente científico" alcançar seus objetivos se colocava sobre a consciência a respeito dos resultados que se poderia alcançar. 
Somente com a clareza obtida pelo cuidado científico ao se educar o corpo o instrutor poderia "desenvolver a robustez dos seus escoteiros por meio de jogos e exercicios ao ar livre" fazendo-o "senão progressivamente e sem antes conhecer a constituição de cada um" (SODRÉ,1923, p.100). Fortuna e Moreira comungam desse posicionamento, mostrando que aqueles instrutores que atuavam como "meros empyricos" causavam grandes "damnos" aos participantes. Tudo isso chocava-se com a diretriz educacional escoteira que propunha exercícios "progressivos, seriados, méthodicos" (FORTUNA; MOREIRA, 1923, p.88).

Torres, depois de constatar que nos grupos escoteiros as necessárias avaliações médicas não eram feitas nos jovens que conhecia (TORRES, 1923, p.77), critica que, no cotidiano dos próprios grupos, era uma constante apenas a avaliação dos jovens para 0 recebimento de suas promoções e prêmios. Ou seja, mais uma vez, acabava-se por repetir um esmero excessivo com o "aspecto espiritual" da formação, negligenciando-se o aspecto corporal manifesto na inquietação médica (TORRES, 1923 p.78). Por isso, Leite fez a proposta de criar uma "ficha médica do escoteiro" (LEITE, 1923, p.87). Apesar do escotismo se construir como possibilidade de reversão de um estado de apatia e crise corporal e moral, a tese em questão defende "a necessidade da selecção medica dos candidatos ao escotismo, regeitando aquelles que não preencherem as condições exigidas para a realisação do ideal escoteiro, a "mens sana in corpore sano" (LEITE, 1923, p.87). Leite (1923) aprofunda a justificativa para essa "medida" da seguinte maneira:

[...] de um corpo doente ou mal cuidado, não se póde esperar a robustez de um caracter, nem uma intelligencia productiva. Assim, de um menino doente e defeituoso não se consegue um bom escoteiro, ou um elemento forte para elevar a raça, quer no terreno materialmente eugenico, quer no intellectual e moral (LEITE, 1923, p.83).

É digno de nota que a reversão dessa situação pela aplicação da ciência na formação dos jovens pudesse deixar de lado todos aqueles que não se adequavam ao "ideal escoteiro". O que, de certo modo, colocava em xeque uma porção nada desprezível das explicações sobre a viabilidade educativa do ideal.

\section{DIFICULDADES PARA A REALIZAÇÃO DO PAPEL PEDAGÓGICO DO ESCOTISMO: 0 MILITARISMO EM QUESTÃO}

Estabelecer, cientificamente, a educação baseada no corpo que ocorreria no interior dos grupos era uma necessidade que evidenciava problemas nas práticas escoteiras. As denúncias de que as "medidas" não eram feitas explicitam que os "avanços da ciência" não tocavam a prática do escotismo, pelo menos não com a mesma veemência com que eram propagadas pelos proponentes e chefes.

Ladeando a imponência do ideário educacional erigido no escotismo, denunciavamse "[...] os perigos das más interpretações", afinal "...toda a medalha tem o seu reverso, e o reverso neste caso, como tambem em tantos outros, póde prejudicar o bom escotismo [...]" (BARROS, 1923, p.234). Especificamente, Barros era incisivo com o que ele chamava de "snobismo", caracterizado pelo extremo zelo com as paradas e o "mostrar-se" em cerimônia, secundarizando os objetivos formativos, avaliados como ponto principal das práticas escoteiras. Tampouco Sodré deixa de criticar em sua tese a desconsideração das intenções educacionais do movimento. Essa desconsideração do fato de ser o escotismo um movimento formativo 
poderia ser vista na atitude dos pais dos escoteiros "quando olham com desinteresse, vendo no escotismo apenas uma diversão, ás vezes perigosa e ás vezes incommoda, que obriga ao desembolso de quantias para a acquisição de uniformes e petrechos" (SODRÉ,1923, p.103).

Cuidando para não minorar a importância desses problemas que maculavam a importância atribuída à proposta de Baden-Powell, o maior esforço dos congressistas se manifestava quando pensavam na influência das práticas militares no escotismo das primeiras décadas do século XX. Ferreira (1923) é um dos congressistas que focalizam a relação entre escotismo, exército e práticas corporais. Mesmo elogiando Olavo Bilac (1923, p.126) por seu estímulo à incorporação de práticas militares na educação, dentre elas as "linhas de tiro", observa que entre elas e as atividades escoteiras havia uma distância muita grande.

Mattos e Ferreira (1923, p.128), afirmam que "O escotismo é a escola em que a creança aprende a ser um bom cidadão. Nelle encontra o joven, ao par dos exercicios physicos, os ensinamentos e os exemplos necessarios a fortificar a sua alma e o seu intellecto", o que the daria condições de defender a pátria. Por fim, arrematam: "[...] o escoteiro não é soldado, mas será se fôr necessario, um bom soldado" (MATTOS; FERREIRA, 1923, p.128). Não obstante mantenham uma postura ambígua no que diz respeito ao relacionamento do escotismo com o "[... estar preparado para a guerra", eles lamentam que as diferenças entre os escoteiros e os soldados não fossem compreendidas "pelos nossos patricios". Essa má compreensão eles viam existir no olhar daqueles que tinham os escoteiros como "soldadinhos de cabo de vassoura" (MATTOS; FERREIRA, 1923, p.128).

Aguiar não se posiciona contra a presença da instrução militar no interior dos grupos escoteiros. Considerava que os escoteiros e os soldados deveriam ser homens "[...] uteis á Patria, como homens de bem, cumpridores de seus deveres, de iniciativa resoluta e caracter recto, sendo assim ambos fortes e unidos por visarem um único fim: o engrandecimento da Patria querida" (AGUIAR, 1923, p.131). Ele ainda afirmava que escoteiros e soldados deveriam ser "capazes de resistir a chuva e ao sol, ao frio e ao calor, sem darem indicios de cansaço ou fadiga, sempre promptos a executarem um exercício ou um serviço qualquer, por mais diffícil que seja; o mesmo acontece com o militar de hoje [...]". Por essa razão via-se nas "crianças de hoje os homens robustos e fortes de amanha..." (AGUIAR, 1923, p.131).

Também se advogava que os aspectos formativos que tinham lugar tanto no escotismo como no exército seriam plenamente realizados sempre que fossem alvo de uma "instrucção individual": "É a instrucção individual exigida como a base da instrucção da tropa, por isso nunca será demasiado o tempo que lhe fôr consagrado: é este o meio de mais tarde realizar-se 0 adestramento colletivo com maior rapidez e efficacia" (AGUIAR, 1923, p.132). A referência à "tropa" também dizia respeito às "tropas" escoteiras.

Em outro aspecto via-se a presença de práticas militares no interior do escotismo: na organização dos desfiles. Era posto em relevo que "É bem verdade que a instrucção escoteira não visa a ostentação nem a belleza de apparencia, mas a utilidade dos ensinamentos, que vão formar das, ageis e de musculos desenvolvidos e rigidos, em condições [...]", sendo assumida, por isso, uma postura pragmática que observava a importância dos desfiles para expansão do escotismo: sumultaneidade, e não a qualidade da tropa que passa e o seu mistér, julgo de 
bom alvitre adoptarmos um certo numero de exercícios para as nossas tropas, e estes devem aquelles a que a nossa gente está acostumada, e não quaesquer innovações de exercicios, de movimentos desordenados, que não têm attractivos em uma exhibição, como o é a parada [sic] (AGUIAR, 1923, p.137).

Na tese de Santos (1923) encontramos a preocupação mais intensa para se estabelecer limites claros entre escotismo e as práticas militares. Ele inicia sua exposição consentindo com o fato de Baden-Powell ter sido um militar e ter concebido o escotismo a partir de suas experiências em guerras. Igualmente, ele reconhece que era frequente o fato de dirigentes e intelectuais que pensavam o movimento negarem relações de proximidade entre escotismo e exército. Entretanto, parece que as coisas não estavam tão separadas no dia a dia dos grupos escoteiros:

Infelizmente, porém, nem tudo o que se affirma, mais ou menos solemnemente, tem na pratica a sua confirmação. Por isso se vê, frequentemente, a errada applicação que, no dominio do escotismo, se faz - e quão largamente - da parte puramente militar da instrucção (SANTOS, 1923, p.206).

O principal problema que isso acarretava era a confusão entre a disciplina fomentada no escotismo e aquela que se exigia dos soldados na caserna. A grande diferença era que a disciplina militar seria "passiva" (SANTOS, 1923, p.206), enquanto a escoteira seria "ativa". Alves (2010, p. 128) nos ajuda a pensar essa manifestação no início do século XX, quando afirma que "[...] diversas facetas da cultura militar" se pautavam na "[...] disciplina, que fundamenta a obediência mais absoluta" (ALVES, 2010, p. 128). Em que pese à "confusão" entre escotismo e militarismo, Santos não deixa de reconhecer que "[...] relações existem entre ambos, possíveis, e, até certo ponto, úteis" (SANTOS, 1923, p.207). Se havia a necessidade do "serviço militar", Santos via que uma das obrigações do escotismo era incutir essa obrigação de modo correto no "caso de defeza da patria". Mesmo assim, os encontros entre as duas esferas eram mais circunstanciais e tocavam detalhes práticos da vida escoteira, como podemos inferir da passagem abaixo:

Entre as diversas noções que se enquadram no ensinamento escoteiro, algumas existem que, de perto ou de longe, coincidem com as noções militares. Umas e outras porém, podem perfeitamente ser ministradas sem o caracter essencial da militança. Taes são, por exemplo, a marcha as diversas posições de attenção ou descanso, o aproveitamente do terreno, as evoluções de agrupamentos em conjunto etc. (SANTOS, 1923, p.207).

Os dois universos distanciar-se-iam quando era considerada a forma com que o corpo e a educação eram assumidos como parâmetros de análises: "Mas todas essas noções devem obedecer mais ao criterio da gymnastica do corpo e do espirito, do sentido de observação, do que a fins propriamente militares" (SANTOS, 1923, p.207). Obviamente, o exército aproveitaria moços bem educados moral e fisicamente, um dos grandes resultados do escotismo. Proporcional à hesitação no estabelecimento de demarcações é a eloquência ao se sublinhar distanciamentos:

D’ahi, porém, a transformar uma tropa escoteira em fracção de companhia ou batalhão; a exigir de escoteiros - que têm o seu programma bem definido - o garbo, a rigidez, o aspecto marcial, é um passo de gigante que o escotismo não deve transpor [sic] (SANTOS, 1923, p.208).

Essas advertências caracterizadas pela vontade de diferenciar ou distanciar, no que era essencial, as duas instituições, lutavam contra uma realidade em que se via existir um 
"abuso que se faz da instrução militar-escotista" (p.209). Tal "abuso" tinha como consequência "não sobrar quase o tempo e a paciência aos instructores para tratarem da parte moral do ensinamento escoteiro, da formação do caracter como organisação affectiva e diamantina, que deve ser - sinão o principal - um dos mais extremos cuidados do instructor" (SANTOS, 1923, p.209). O grande índice utilizado para verificar esse "descuido" com o "ensinamento escoteiro", mais uma vez, era a forma como as atividades corporais utilizadas pelos grupos acabavam por se tornar, tipicamente, militarescas, afastando-se tanto da "gymnastica" quanto dos "sports":

\footnotetext{
Chegámos, assim, ao resvalar do escotismo por uma verdadeira inclinação, que o conduz á organisação militar, em toda a accepção do termos, das patrulhas transformadas em esquadras. E o deslise se opera do seguinte modo: começando pela gymnastica, que, aos poucos, se vae desenvolvendo em lições de box e de esgrima de bastões, jogo do pau, marchas guerreiras, toques de corneta e tambor regulamentares, acampamentos militarisados, com toda a sua sequencia de quartos de sentinella, rondas, estados maior e menor, ordens do dia, de detalhe e de serviço, etc. [sic] (SANTOS, 1923, p.210).
}

O corolário mais concreto dessa "militarisação continuada" seria que o "verdadeiro escotismo, aquelle que robustece os corpos, ennobrecendo a alma", acabava por se tornar um conjunto de práticas para "soldados á paisana", nas quais "desapareceu o espirito vivificante do escotismo, a pureza dos seus principios e a pratica de suas virtudes!" (SANTOS, 1923, p.210211). Conclamou-se, em letras maiúsculas: os chefes escoteiros deveriam lutar contra a sombra militaresca "REAGINDO!" (SANTOS, 1923, p.211): "Reagindo, enfim, pela suppressão de tudo quanto, sem proveito immediato para o corpo e para o espírito do menino, póde desapparecer da esphera do escotismo, com especialidade as manifestações exteriores". Explicita-se, assim, a maneira como se contrapunha o distanciamento das práticas militares com o que era "[...] sem proveito immediato para o corpo e o espírito do menino" (SANTOS, 1923, p.211).

Não se tratava de divulgar um "espírito antimilitarista". Valorizava-se a importância do exército e do soldado, deixando claro, todavia, que o desejo de "[....] ver em cada cidadão um soldado" (SANTOS, 1923, p.212) não significava aprovar a ideia de formar "escoteirossoldados". Caso isso acontecesse, estaria em questão o "[...] preparo militar de nossa Pátria" pela indevida presença de valores e práticas da caserna em um momento em que a "pedagogia científica" deveria ser a grande guia. Pedagogia que buscava o desenvolvimento moral nas atividades corporais baseadas na "gymnastica", nos jogos e nos "sports", e não na mera repetição daquilo que se esperava de soldados durante seu treinamento para as lidas nos campos de batalha. No torvelinho dos limites entre a "cultura militar" (ALVES, 2010) e a cultura especificamente pedagógica atenta ao corpo, havia um "consumo e produção da cultura pedagógica que estava em circulação, para produzir saberes que pudessem ser utilizados na educação da juventude" (FERREIRA NETO; SCHNEIDER, 2010, p.163). 0 exército e a pedagogia tiveram suas práticas e prescrições processadas para se produzir a educação corporal existente no seio do escotismo.

\section{CONSIDERAÇÕES FINAIS}

A leitura das teses apresentadas nos dois congressos escoteiros aqui analisados permite verificar que a dimensão corporal da educação foi posta como um dos principais pilares para fazer frente a uma situação de crise social. Essa crise foi diagnosticada a partir do que 
os chefes escoteiros e professores participantes dos congressos viram como um excessivo predomínio do intelecto, do cérebro, do espírito. Traço reforçado pelas práticas e instituições educacionais existentes, em socorro das quais o escotismo providenciaria a panaceia reconhecendo a natureza (corporal) das crianças e jovens.

Todavia, representar o corpo e as práticas corporais como "pedagogia científica" não era o suficiente. Tentou-se delimitar espaços com o exército, outra instituição que dava grande peso ao corpo para a formação de seus quadros. Embora a coragem do guerreiro e seus feitos ainda continuassem como importantes modelos formativos para a juventude, para os presentes nos congressos, a disciplina e as atividades corporais da caserna não serviriam para o alcance desses objetivos pedagógicos. Pelo menos, não nos moldes colocados pela pedagogia.

Ao legitimarem suas ideias pela aproximação às reflexões dos pedagogos, os dirigentes escoteiros valorizaram (ou, tentaram fazer valorizar) os jogos, as brincadeiras, os "sports" como recursos pedagógicos, em detrimento do uso "empyrico" que viam existir na forma com que o corpo e suas atividades eram considerados nos exércitos. Se essa separação entre diferentes "culturas" (ALVES, 2010) não se dava tranquilamente no campo das ideias pedagógicas circulantes, evidencia-se que a educação corporal, o escotismo e o militarismo imbricavamse no cotidiano dos diferentes agrupamentos escoteiros espalhados pelo país nas primeiras décadas do século XX. Afinal, "[...] o trabalho de Baden-Powell foi visto como uma possibilidade consoante com os propósitos do exército" (FERREIRA NETO; SCHNEIDER, 2010, p.162163). Ambos, exército e escotismo, abraçaram a defesa de uma educação pautada em uma "pedagogia da ação prática", herdeira de uma tradição que seguia "[...] Jean-Jacques Rousseau, William James, John Dewey, Edouard Claparède". Dito de outro modo, o fato de a educação corporal "ter chancela militar" não deve pôr em segundo plano rupturas em relação aos limites procedimentais do exército. A educação corporal foi assumida, também, pelo escotismo e pela pedagogia escolar, no início do século XX. Essa conclusão permite-nos visualizar que o corpo e suas práticas aglutinam representações que ora se chocam, ora se fundem, destacando que 0 valor dessa "dimensão" (TABORDA DE OLIVEIRA; LINHALES, 2011) educacional na realização de ambições educacionais do período não se concretizou sem embates.

\section{REFERÊNCIAS}

AGUIAR, Jurucey de. A instrucção militar no Escoteirismo. In: ASSOCIAÇÃO DE ESCOTEIROS CATHOLICOS DO BRAZIL. Primeiro e segundo congressos escoteiros do Brasil - 1922-1923 Primeiro e segundo "jamborées" brazileiros - theses e relatorios. Rio de Janeiro: Typograhia d'o pharol, 1923. p.131-141.

ALVES, Claudia. Exército e cultura escolar no Brasil do século XIX. In: ALVES, Claudia; NEPOMUCENO, Mari de Araújo (Orgs.). Militares e educação em Portugal e no Brasil. Rio de Janeiro: FAPERJ: Quartet, 2010. p.125-138.

AMARAL, Aureliano. Escotismo ou Escoteirismo? In: ASSOCIAÇÃO DE ESCOTEIROS CATHOLICOS DO BRAZIL. Primeiro e segundo congressos escoteiros do Brasil - 1922-1923 - Primeiro e segundo "jamborées" brazileiros - theses e relatorios. Rio de Janeiro: Typograhia d'o pharol, 1923. p.225-229.

ASSOCIAÇÃO DE ESCOTEIROS CATHOLICOS DO BRAZIL. Primeiro e segundo congressos escoteiros do Brasil - 1922-1923 - Primeiro e segundo "jamborées" brazileiros - theses e relatorios. Rio de Janeiro: Typograhia d'o pharol, 1923. 
BARROS, David de. O sport no escotismo. In: ASSOCIAÇÃO DE ESCOTEIROS CATHOLICOS DO BRAZIL. Primeiro e segundo congressos escoteiros do Brasil - 1922-1923 - Primeiro e segundo "jamborées" brazileiros - theses e relatorios. Rio de Janeiro: Typograhia d'o pharol, 1923.p.232237.

BOURZAC, Albert. Les bataillons scolaires 1880-1891: l'éducation militaire à l'école de la République. Paris: L'Harmattan, 2004.

CHARTIER, Roger. A História Cultural: entre práticas e representações. Rio de Janeiro: Bertrand Brasil, 2002.

CARVALHO, Marta Maria Chagas de; HANSEN, João Adolfo. Modelos culturais e representação: uma leitura de Roger Chartier, Varia Historia, Belo Horizonte, n.16, p.7-24, 1996.

CURSON, Diniz A. O escoteirismo e o estudo do seu ambiente social. In: ASSOCIAÇÃO DE ESCOTEIROS CATHOLICOS DO BRAZIL. Primeiro e segundo congressos escoteiros do Brasil - 1922-1923 - Primeiro e segundo "jamborées" brazileiros - theses e relatorios. Rio de Janeiro: Typograhia d'o pharol, 1923. p.58-65.

FERREIRA, Cyro Nunes. A instrucção militar e os escoteiros no Brasil. In: ASSOCIAÇÃO DE ESCOTEIROS CATHOLICOS DO BRAZIL. Primeiro e segundo congressos escoteiros do Brasil - 1922-1923 - Primeiro e segundo "jamborées" brazileiros - theses e relatorios. Rio de Janeiro: Typograhia d'o pharol, 1923. p125-129.

FERREIRA NETO, Amarílio; SCHNEIDER, Omar. Prescrições e representações sobre a educação física brasileira: o ensino no Exército e na escola. In: ALVES, Cláudia; NEPOMUCENO, Maria de Araújo (Orgs.). Militares e educação em Portugal e no Brasil. Rio de Janeiro: FAPERJ: Quartet, 2010. p.139-168.

FORTUNA, João Evangelista Peixoto. Religião e Escoteirismo. In: ASSOCIAÇÃO DE ESCOTEIROS CATHOLICOS DO BRAZIL. Primeiro e segundo congressos escoteiros do Brasil - 1922-1923 Primeiro e segundo "jamborées" brazileiros - theses e relatorios. Rio de Janeiro: Typograhia d'o pharol, 1923. p.185-193.

HEROLD JUNIOR, Carlos; VAZ, Alexandre Fernandez. Educação corporal, escotismo e militarismo (1908-1941), Movimento, Porto Alegre, v.21, n.4, p.1011-1023, 2015.

HORTA, José Silvério Baía. O hino, o sermão e a ordem do dia: a educação no Brasil (1930-1945). Rio de Janeiro: Editora UFRJ, 1994.

LEITE, Rodrigo de Lamare. Necessidade da inspecção medica do escoteiro. In: ASSOCIAÇÃO DE ESCOTEIROS CATHOLICOS DO BRAZIL. Primeiro e segundo congressos escoteiros do Brasil - 1922-1923 - Primeiro e segundo "jamborées" brazileiros - theses e relatorios. Rio de Janeiro: Typograhia d'o pharol, 1923, p.83-90.

MONZON, Mario. Contribuição para o ensino da educação physica. In: ASSOCIAÇÃO DE ESCOTEIROS CATHOLICOS DO BRAZIL. Primeiro e segundo congressos escoteiros do Brasil - 1922-1923 - Primeiro e segundo "jamborées" brazileiros - theses e relatorios. Rio de Janeiro: Typograhia d'o pharol, 1923. p.68-76.

RAMOS, Manoel Paiva. Os exercicios fisicos e a defeza pessoal. In: ASSOCIAÇÃO DE ESCOTEIROS CATHOLICOS DO BRAZIL. Primeiro e segundo congressos escoteiros do Brasil - 1922-1923 Primeiro e segundo "jamborées" brazileiros - theses e relatorios. Rio de Janeiro: Typograhia d'o pharol, 1923. p.239-263.

SANTOS, Benvenuto Cellini dos Santos. Militarisação do Escotismo. In: ASSOCIAÇÃO DE ESCOTEIROS CATHOLICOS DO BRAZIL. Primeiro e segundo congressos escoteiros do Brasil - 1922-1923 - Primeiro e segundo "jamborées" brazileiros - theses e relatorios. Rio de Janeiro: Typograhia d'o pharol, 1923. p.205-215. 
SKINNER, Gabriel. O escotismo sob o ponto de vista da educação physica. In: ASSOCIAÇÃO DE ESCOTEIROS CATHOLICOS DO BRAZIL. Primeiro e segundo congressos escoteiros do Brasil - 1922-1923 - Primeiro e segundo "jamborées" brazileiros - theses e relatorios. Rio de Janeiro: Typograhia d'o pharol, 1923. p. 217-224.

SODRÉ, Benjamin. Do registro completo do escoteiro. In: ASSOCIAÇÃO DE ESCOTEIROS CATHOLICOS DO BRAZIL. Primeiro e segundo congressos escoteiros do Brasil - 1922-1923 Primeiro e segundo "jamborées" brazileiros - theses e relatorios. Rio de Janeiro: Typograhia d'o pharol, 1923. p.99-111.

SODRÉ, Benjamin; SKINNER, Gabriel. Concessão do premio nobel ao General Baden-Powell. In: ASSOCIAÇÃO DE ESCOTEIROS CATHOLICOS DO BRAZIL. Primeiro e segundo congressos escoteiros do Brasil - 1922-1923 - Primeiro e segundo "jamborées" brazileiros - theses e relatorios. Rio de Janeiro: Typograhia d'o pharol, 1923. p.146-147.

SPRINGHALL, John. The boy scouts, class and militarism in relation to British youth movements 19081930, International Review of Social History, Cambridge v.16, n.2, p.125-158,1971.

TABORDA DE OLIVEIRA, Marcus Aurélio; LINHALES, Meily Assbú. Pensar a educação do corpo na e para a escola: indícios no debate educacional brasileiro (1882-1927). Revista Brasileira de Educação, Rio de Janeiro, v. 16, p. 389-407, 2011.

TORRES, Ambrosio. Vantagens e perigos da gymnastica e dos sports. In: ASSOCIAÇÃO DE ESCOTEIROS CATHOLICOS DO BRAZIL. Primeiro e segundo congressos escoteiros do Brasil - 1922-1923 - Primeiro e segundo "jamborées" brazileiros - theses e relatorios. Rio de Janeiro: Typograhia d'o pharol, 1923. p.77-81. 


\section{Apoio:}

O trabalho contou com o apoio do CNPQ e da Fundação Araucária 